\title{
Extramedullary Plasmacytoma of Nasal Cavity
}

\author{
${ }^{1}$ Swati Tandon, ${ }^{2}$ Ravi Meher, ${ }^{3}$ Anju Chauhan
}

\section{ABSTRACT}

Extramedullary plasmacytoma is a rare neoplasm characterized by monoclonal proliferation of plasma cells in soft tissues. Extramedullary plasmacytomas constitute 3 to $5 \%$ of all plasma cell neoplasms. Most lesions occur in the head and neck, primarily in the upper aerodigestive tract, with $75 \%$ occurring in nose and paranasal sinuses. To the best of our knowledge, only few cases of sinonasal extramedullary plasmacytomas have been reported in the literature. It is important for otolaryngologists to acquire knowledge of this disease as 80 to $90 \%$ occur in the head and neck region. We report a rare case of extramedullary plasmacytoma of the nasal cavity in a 60-year-old male managed by surgery and radiotherapy.

Keywords: Extramedullary plasmacytoma, Nose, Paranasal sinuses.

How to cite this article: Tandon S, Meher R, Chauhan A. Extramedullary Plasmacytoma of Nasal Cavity. Clin Rhinol An Int J 2016;9(1):50-52.

Source of support: Nil

Conflict of interest: None

\section{INTRODUCTION}

Plasma cell neoplasms are monoclonal expansions of single late-stage B-lymphocytes with predisposition to mature into plasma cells. All the differentiated cells within the neoplasm produce the same immunoglobulin chain. Approximately 5\% of myelomas originate in extraskeletal sites. Majority of extramedullary plasmacytomas develop in the head and neck region, most common being the nasal cavity and septum. ${ }^{1}$ They usually occur in the 5th to 6th decade of life and demonstrate 4:1 male predominance. The diagnosis is based on histological confirmation of monoclonal plasma cell proliferation of a single disease site and exclusion of multiple myeloma. Most extramedullary plasmacytomas respond well to radiotherapy (30-35 Gy) delivered in 12 to 15 fractions along with surgery, if feasible. We describe a rare case of solitary nasal plasmacytoma treated by surgery and radiotherapy.

\footnotetext{
${ }^{1}$ Senior Resident, ${ }^{2}$ Professor, ${ }^{3}$ Resident

${ }^{1-3}$ Department of ENT, Maulana Azad Medical College New Delhi, India

Corresponding Author: Swati Tandon, Senior Resident Department of ENT, Maulana Azad Medical College, New Delhi, India, Phone: +919891778593, e-mail: drswatitandon86@ gmail.com
}

\section{CASE REPORT}

A 60-year-old male presented to the otolaryngological department of our hospital with complaints of nasal obstruction and epistaxis from left nasal cavity for 1.5 years. It was associated with nasal discharge from the left nasal cavity occasionally and anosmia on the left side. There were no associated ocular, oral, or aural complaints. There was no history of occupational exposure to irritants or smoking. There was no associated comorbidity. On examination of the nose, a pink polypoidal mass was seen in the left nasal cavity, reaching anteriorly up to the vestibule. On probing, the mass was nontender, bled on touch, and was found to be arising from the lateral nasal wall. Contrast-enhanced computed tomography scan of the nose and paranasal sinuses revealed homogenously enhancing soft tissue mass in the left nasal cavity with partial obliteration of choana. The mass was seen to be eroding the medial wall of orbit without intraconal invasion. It filled filling the ethmoids, with blockage of the left maxillary sinus ostia with no intracranial extension (Fig. 1). A biopsy of the nasal mass was done under local anesthesia, which revealed it to be plasmacytoma. The patient was then investigated to rule out multiple myeloma. Urine electrophoresis was negative for M-band. Bone marrow aspirate and biopsy reports were inconsistent for multiple myeloma. TC-99 bone scintigraphy was done, which did not reveal any lytic lesions. Therefore,

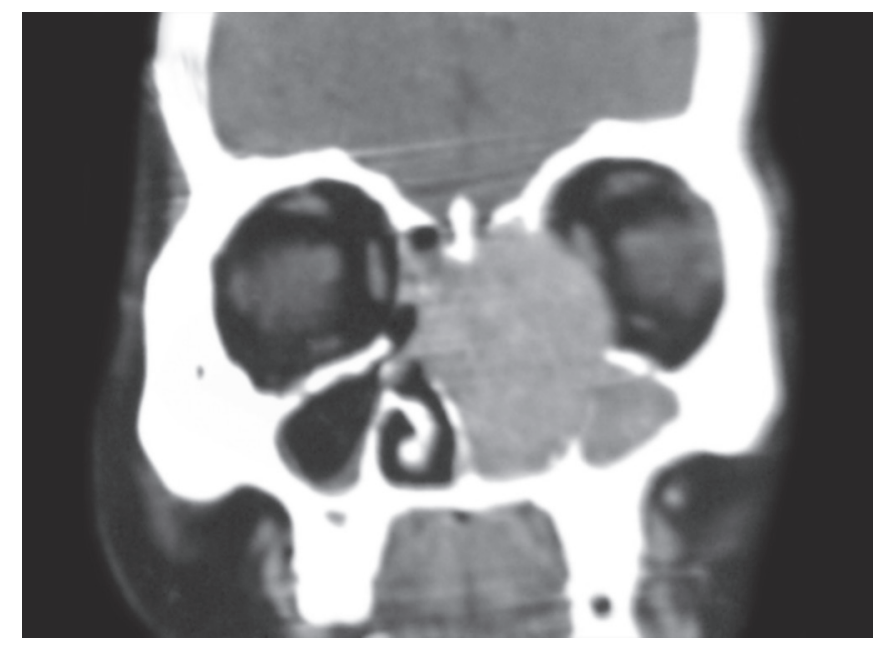

Fig. 1: Contrast-enhanced computed tomography paranasal sinus showing homogenously enhancing mass in the left nasal cavity without intraorbital and intracranial extension 


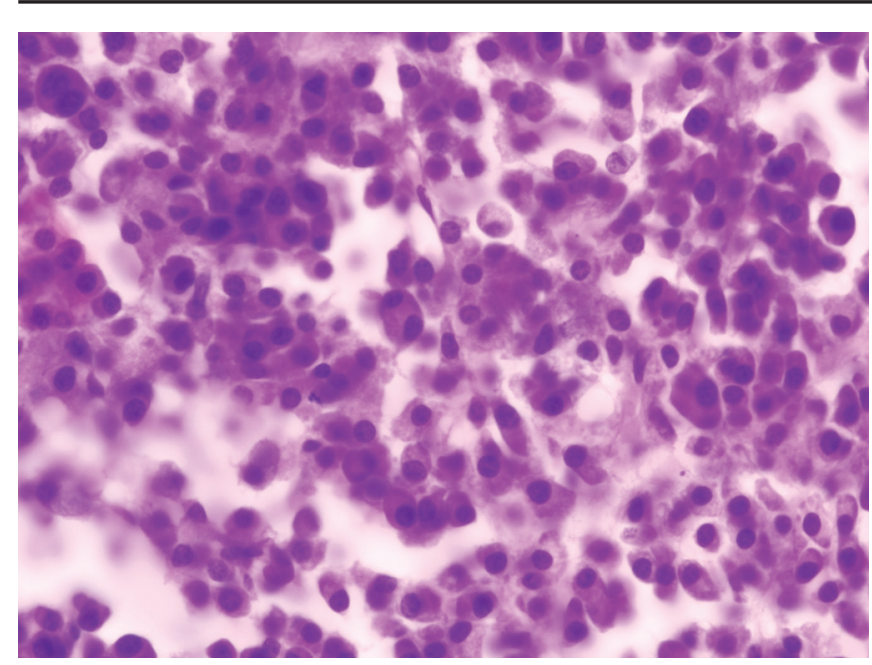

Fig. 2: Sheets on mature and immature plasma cells with few binucleate form (hematoxylin and eosin $400 \times$ )

a diagnosis of solitary nasal plasmacytoma was made and endoscopic excision of the mass was done under general anesthesia. Postoperatively, the patient received 30 Gy of radiotherapy. Histopathological examination of the specimen revealed it to be plasmacytoma, in which tumor cells expressed kappa light chains, and the result was negative for lambda light chains (Fig. 2). The patient is on regular follow-up and is free from the disease.

\section{DISCUSSION}

Plasmacytoma is a rare solitary mass of neoplastic monoclonal plasma cells, first described by Schridde in $1905 .^{2}$ Plasmacytomas have been classified into five types: Multiple myeloma, solitary plasmacytoma, extramedullary plasmacytoma, nonsecretory myeloma, and plasma cell leukemia. Multiple myeloma is a disseminated disease with predilection for marrowcontaining bones. Solitary myeloma is a localized form of neoplastic cell proliferation that produces a solitary destructive bone lesion. Approximately $70 \%$ progress to disseminated disease. Nonsecretory myelomas are characterized by plasma cells that synthesize but do not secrete immunoglobulin molecules, resulting in the absence of paraprotein. Plasma cell leukemia is defined as a level of plasma cells in the peripheral blood that exceeds $2 \times 10^{9} /$ l. Extramedullary plasmacytomas are extraosseous proliferation of cells in soft tissues, majority arising in the upper respiratory tract. Other sites of involvement include the gastrointestinal tract, breasts, thyroid, ${ }^{3}$ testis, bladder, retroperitoneum, and lymph nodes. The etiology of nasal plasmacytoma remains unknown, but factors, such as viral pathogenesis and chronic irritation from inhaled irritants have been indicated. ${ }^{4}$ The symptoms of extramedullary plasmacytomas depend on the site and extent of the lesion. In our case, since the mass was confined to the nasal cavity only, the patient presented with nasal obstruction and epistaxis.

Amyloidosis, a complication of plasmacytoma, characterized histopathologically by the extracellular deposition of insoluble fibrillar proteins, has been described in the literature. Amyloid deposition may be seen in 15 to $38 \%$ of extramedullary plasmacytoma. In a case report of extramedullary plasmacytoma of duodenum, ${ }^{5}$ amyloidosis was caused by the deposition of immunoglobulin light chains since both amyloid and plasma cells share the same immunoglobulin light chain restriction (lambda restriction). In our case, there was no feature of amyloidosis.

In our case, since the tumor was well localized in the nasal cavity and ethmoids, it was excised endoscopically in totality, followed by radiotherapy. Laser excision of well-localized tumors has also been described. ${ }^{6}$ These tumors are usually treated with radiotherapy. Doses of 40 to 50 Gy are used. Local control is usually excellent with response rates described above $90 \%{ }^{7}$ A pathological grading system based on the multiple myeloma grading criteria has been proposed where tumors are classified into low, intermediate, and high grades. It has been found to correlate closely with outcomes.

The use of adjuvant chemotherapy in patients with higher-grade disease is recommended. ${ }^{4}$ Follow-up of these patients is important as a chance to develop multiple myeloma exists, although at a far lower rate than solitary plasmacytomas.

\section{CONCLUSION}

Extramedullary plasmacytoma is a rare tumor of the nasal cavity. Our case demonstrates that a multidisciplinary approach is required for the diagnosis and treatment. Prognosis is much better than multiple myeloma. Patients should always be monitored for a long time.

\section{REFERENCES}

1. Ashraf MJ, Azarpira N, Khademi B, Abedi E, Hakimzadeh A, Valibeigi B. Extramedullary plasmacytoma of the nasal cavity: report of three cases with review of the literature. Iran Red Crescent Med J 2013 Apr;15(4):363-366.

2. Attansio G, Viccaro M, Barbaro M, De Seta E, Filipo R. Extramedullary plasmacytoma of paranasal sinuses. A combined therapeutic strategy. Acta Otorhinolaryngol Ital 2006 Apr;26(2):118-120.

3. Puliga G, Olla L, Bellisano G, Di Naro N, Ganau M, Lai ML, Faa G, Tolu GA. Solitary extramedullary plasmacytoma of the thyroid gland associated with multinodular goiter: case report and review of the literature. Pathologica 2011 Jun;103(3):61-63. 
4. Chang YL, Chen PY,Hung SH. Extramedullary plasmacytoma of the nasopharynx: a case report and review of the literature. Oncol Lett 2014 Feb;7(2):458-460.

5. Carneiro FP, Sobreira MN, Maia LB, Sartorelli AC, Franceschi LE, Brandão MB, Calaça BW, Lustosa FS, Lopes JV. Extramedullary plasmacytoma associated with a massive deposit of amyloid in the duodenum. World J Gastroenterol 2009 Jul 28;15(28):3565-3568.
6. Hazarika P, Balakrishnan R, Singh R, Pujary K, Aziz B. Solitary extramedullary plasmacytoma of sinonasal region. Indian J Otolaryngol Head Neck Surg 2011 Jul;63(Suppl 1): 33-35.

7. Webb M, Barrett C, Barrett S, van Rensburg JJ, Louw V. Cranial plasmacytoma: a case series and review of the literature. Indian J Hematol Blood Transfus 2013 Mar; 29(1):43-47. 